species to Sindbis virus. Am. J. Trop. Med. Hyg. 23:131-134.

31.Wang, S. and T. Hazelrigg. 1994. Implications for bed mRNA localization from spatial distribution of exu protein in Drosophila oogenesis. Nature 369:400-403.

This work was supported by Grant Nos. AI-37671, AI-28781 and AI-34014 from the NIH, by a grant from the John D. and Catherine T. MacArthur Foundation and by a CRC grant from Colorado State University. Anopheles gambiae mosquitoes were kindly supplied by Dr. F.H. Collins (Centers for Disease Control and Prevention, Atlanta, GA). Address correspondence to Stephen Higgs, The Arthropod-borne and Infectious Diseases Laboratory, Foothills Campus, Colorado State University, Fort Collins, CO, 80523-1682 USA. Internet: shiggs@vines.colostate.edu

Received 15 March 1996; accepted 21 May 1996.

S. Higgs, D. Traul, B.S. Davis,
K.I. Kamrud, C.L. Wilcox and
B.J. Beaty
Colorado State University
Fort Collins, CO, USA

S. Higgs, D. Traul, B.S. Davis, K.I. Kamrud, C.L. Wilcox and B.J. Beaty Fort Collins, CO, USA

\section{Fluorometric Assay for DNA Polymerases and Reverse Transcriptase}

BioTechniques 21:664-672 (October 1996)

\begin{abstract}
We report a quick, easy and inexpensive fluorometric assay that measures the activity of replication enzymes using PicoGreen $^{\mathrm{TM}}$. The systems tested include replication of the natural template M13 Gori by E. coli DNA polymerase III holoenzyme and the replication of a synthetic homopolymer by human immunodeficiency virus reverse transcriptase. A direct comparison of the fluorometric assay with the conventional isotopic assay shows that the fluorometric assay accurately reflects the extent of replication. By performing the assay reactions directly in 96-well plates and using a fluorescence plate reader to determine the extent of reaction, the time required to measure replication activities is significantly shortened.
\end{abstract}

\section{INTRODUCTION}

Conventional assays of polymerase activity involve measuring the extent of incorporation of radiolabeled nucleotides into acid-insoluble polynucleotides $(5,6,8)$. Such procedures are cumbersome and time-consuming because of the need to separate incorporated and free nucleotides by a series of filtration and washing steps.

Several spectroscopic assays have been introduced recently. These include a reverse transcriptase (RT) assay that uses 4',6-diamidino-2-phenylindole, the fluorescence of which is enhanced by binding to poly (A) p poly(dT) during the course of the reaction (1). The fluorescence of this dye is unchanged in the presence of double-stranded DNA (dsDNA) and, therefore, cannot be used to assay conventional DNA-dependent DNA polymerases (1).

To detect transient intermediates in the reactions catalyzed by $E$. coli DNA polymerase I and T4 DNA polymerase, Frey et al. (3) have used changes in the fluorescence of the base analog 2aminopurine upon incorporation into
DNA. In a different approach, Griep (4) has recently described a fluorometric assay for E. coli DNA polymerase III holoenzyme based on changes in the fluorescence of single-stranded (ss) DNA-binding protein (SSB) during DNA replication. However, this assay is limited to systems requiring SSB.

The fluorescence of the recently introduced dye PicoGreen ${ }^{\mathrm{TM}}$ is enhanced specifically upon binding to dsDNA, and it is relatively nonfluorescent in the presence of ssDNA. Here, we report a quick, easy, sensitive and inexpensive fluorometric assay, utilizing PicoGreen, that can be used to monitor the synthesis of both dsDNA and DNA:RNA hybrids and is, therefore, applicable to a wide range of DNA polymerases and reverse transcriptases.

\section{MATERIALS AND METHODS}

E. coli DNA polymerase III holoenzyme (pol III holoenzyme), human immunodeficiency virus (HIV) RT, dnaG primase, SSB and M13 Gori DNA are commercially available from Enzyco (Denver, CO, USA). PicoGreen was obtained from Molecular Probes (Eugene, OR, USA). Synthetic polynucleotides were obtained from Pharmacia Biotech (Piscataway, NJ, USA).

\section{Fluorescence Instrumentation}

Fluorescence measurements were made using either an SLM Model 48000 fluorometer (SLM Instruments, Urbana, IL, USA) or an SLT Fluorostar microplate fluorometer (SLT Labinstruments, Research Triangle Park, NC, USA). The SLM fluorometer was configured with excitation and emission wavelengths of 500 and $526 \mathrm{~nm}$, respectively. The slit widths were varied between 4 and $16 \mathrm{~nm}$. All measurements were performed at room temperature except where noted. The SLT microplate fluorometer was equipped with 485 and $538 \mathrm{~nm}$ interference filters on excitation and emission, respectively.

\section{Solutions}

Pol III holoenzyme primer-template solution: $60 \mathrm{mM}$ HEPES, $\mathrm{pH}$ 7.5, $14 \mathrm{mM}$ magnesium acetate, 2.8 mM ATP, GTP, CTP and UTP, 14\% 
Table 1. Protocol for the Fluorometric Assay of Pol III Holoenzyme Using a Plate Reader

1. Combine the pol III holoenzyme polymerization solution and primer-template in the ratio $7: 1$ in sufficient quantities for the number of assays to be performed. This mixture is stable on ice for $>2 \mathrm{~h}$.

2. On ice, add $24 \mu \mathrm{L}$ of the above solution into a 96 -well plate with round-bottom wells.

3. Add $1 \mu \mathrm{L}$ pol III holoenzyme to each reaction.

4. Mix by shaking for $10-15 \mathrm{~s}$ on a flat surface.

5. Cover and place in a $30^{\circ} \mathrm{C}$ water bath or heater block for $5 \mathrm{~min}$.

6. Add $200 \mu \mathrm{L}$ of a 1:400 dilution of PicoGreen in TE buffer to each well.

7. Quantitate the extent of replication in a fluorescence plate reader after 5-15 min incubation at room temperature.

glycerol, $56 \mathrm{mM} \mathrm{NaCl}, 42 \mathrm{mM}$ potassium glutamate, $84 \mu \mathrm{g} / \mathrm{mL}$ bovine serum albumin (BSA) and $4 \mathrm{mM}$ dithiothreitol (DTT).

Pol III holoenzyme polymerization solution: $180 \mathrm{mM}$ bicine, $\mathrm{pH} 8.0$, $25 \%$ glycerol, $0.017 \%$ Nonidet $^{\circledR}$ P-40 (NP40), $170 \mu \mathrm{g} / \mathrm{mL}$ BSA, $83 \mu \mathrm{mM}$ potassium glutamate, $8 \mathrm{mM}$ DTT, 2.3 $\mathrm{mM}$ magnesium acetate, $10 \mu \mathrm{g} / \mathrm{mL}$ rifampicin, $57 \mu \mathrm{M}$ each of dGTP, dATP and dCTP, and $21 \mu \mathrm{M}\left[{ }^{3} \mathrm{H}\right] \mathrm{TTP}$ (235 $\mathrm{cpm} / \mathrm{pmol})$. The radioisotope was included in the assays to allow a direct comparison of the isotopic and fluorometric assays.

Pol III holoenzyme dilution buffer: $50 \mathrm{mM}$ HEPES, $\mathrm{pH}$ 7.5, 20\% glycerol, $0.02 \%$ NP40, $200 \mu \mathrm{g} / \mathrm{mL}$ BSA,
$100 \mathrm{mM}$ potassium glutamate and 10 mM DTT.

RT primer-template buffer: 10 $\mathrm{mM}$ Tris-HCl, $\mathrm{pH}$ 8.1, 0.5 mM EDTA.

RT polymerization solution: 63 $\mathrm{mM}$ Tris-HCl, $\mathrm{pH} 8.1,8 \mathrm{mM} \mathrm{MgCl}_{2}$, $132 \mathrm{mM} \mathrm{NaCl}, 13 \mathrm{mM}$ DTT, $112 \mu \mathrm{M}$ $\left[{ }^{3} \mathrm{H}\right] \mathrm{TTP}(260 \mathrm{cpm} / \mathrm{pmol})$.

RT dilution buffer: $50 \mathrm{mM}$ Tris$\mathrm{HCl}, \mathrm{pH} 7.5,20 \%$ glycerol, $2 \mathrm{mM}$ DTT.

\section{Preparation of Primer-Templates}

Prepare sufficient primer-template for 100 pol III holoenzyme reactions as follows: mix $243 \mu \mathrm{L}$ of primer-template solution, 7.2 $\mu \mathrm{L}$ M13 Gori (2.98 $\mathrm{mg} / \mathrm{mL}), 63 \mu \mathrm{L} \mathrm{SSB}(2.2 \mathrm{mg} / \mathrm{mL})$ and $27 \mu \mathrm{L}$ dna $\mathrm{G}$ primase $(0.39 \mathrm{mg} / \mathrm{mL})$.

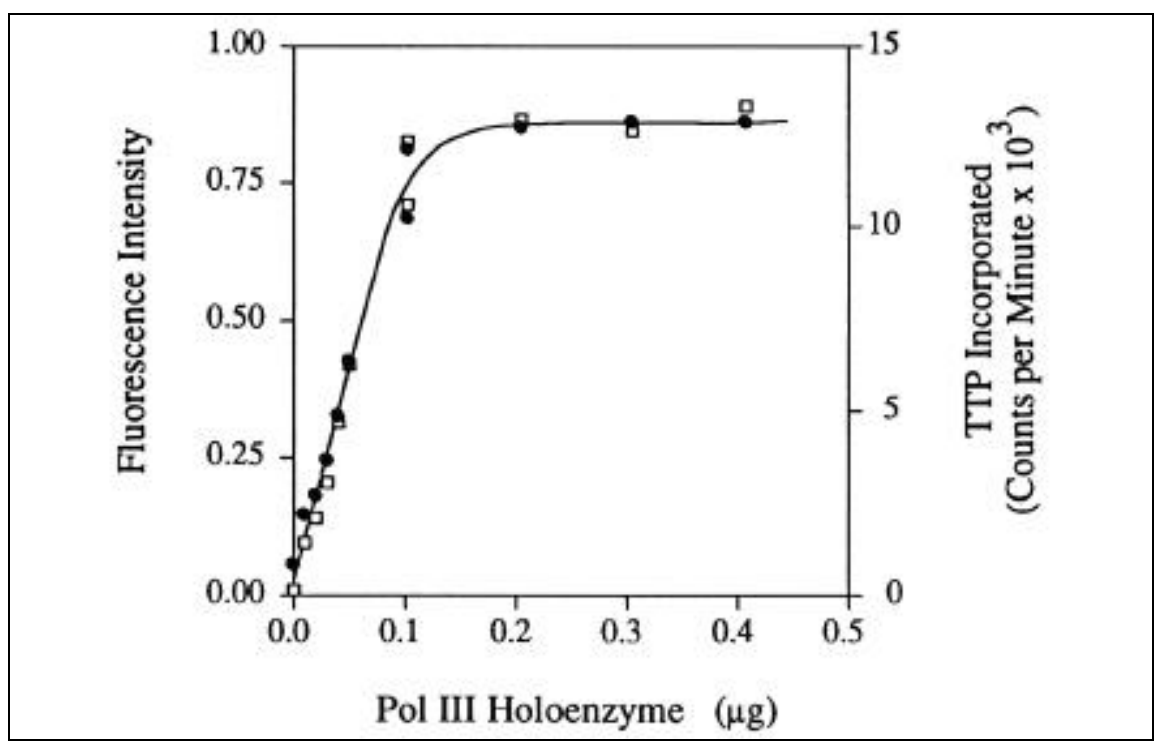

Figure 1. Comparison of the fluorometric and isotopic assays for pol III holoenzyme. Various amounts of pol III holoenzyme were added to primed M13 Gori (see Materials and Methods). After a 5min incubation, aliquots from the reactions were subject to either the PicoGreen fluorometric assay (•) or the conventional isotopic assay ( $\square$ ). 
Incubate for $15 \mathrm{~min}$ at $30^{\circ} \mathrm{C}$. This mixture is stable on ice for $>5 \mathrm{~h}$.

Prepare sufficient primer-template for $100 \mathrm{RT}$ reactions as follows: mix 10 $\mu \mathrm{L}$ poly $(\mathrm{rA})_{350}(10 \mathrm{mg} / \mathrm{mL}$ in $\mathrm{RT}$ primer-template buffer) and $38.6 \mu \mathrm{L}$ oligo $(\mathrm{dT})_{16}(130 \mu \mathrm{g} / \mathrm{mL}$ in the same buffer) and incubate for $1 \mathrm{~h}$ at room temperature. Then bring the final volume to $200 \mu \mathrm{L}$ with $\mathrm{RT}$ primer-template buffer.

\section{Polymerization Reaction Conditions}

For pol III holoenzyme assays, add, on ice, $3 \mu \mathrm{L}$ of primer-template to 21 $\mu \mathrm{L}$ of polymerization reaction solution and mix. Add $1 \mu \mathrm{L}$ of an appropriate dilution of pol III holoenzyme. Incubate at $30^{\circ} \mathrm{C}$ for $5 \mathrm{~min}$. Stop the reaction by placing on ice and immediately adding $1 \mu \mathrm{L}$ of $0.25 \mathrm{M}$ EDTA.

For RT assays, add, on ice, $2 \mu \mathrm{L}$ of primer-template to $38 \mu \mathrm{L}$ of polymerization reaction solution and mix. Add $10 \mu \mathrm{L}$ of an appropriate dilution of RT. Incubate at $37^{\circ} \mathrm{C}$ for $10 \mathrm{~min}$. Stop the reaction by placing on ice and immediately adding $5 \mu \mathrm{L}$ of $0.2 \mathrm{M}$ EDTA.

\section{Isotopic Assay of Polymerization}

The precipitation of polynucleotide, removal of unincorporated nucleotide triphosphates and scintillation counting were performed as previously described (8).

\section{Fluorometric Assay of Polymerization}

For single time-point assays of the polymerase reactions using a SLM 48000 fluorometer, add $5 \mu \mathrm{L}$ (RT) or $10 \mu \mathrm{L}$ (pol III holoenzyme) of EDTAterminated reaction mixture to $1 \mathrm{~mL}$ of a 1:400 dilution of PicoGreen in TE buffer (10 mM Tris-HCl, pH 7.5, $1 \mathrm{mM}$ EDTA). Read the samples in a $10-\mathrm{mm}$ path-length cuvette, 5-15 min after adding the dye.

For continuous monitoring of Pol III holoenzyme activity, polymerization reactions are performed directly in a SLM fluorometer in a 3-mm pathlength cuvette at $30^{\circ} \mathrm{C}$ containing 88 $\mu \mathrm{L}$ of the replication reaction buffer and $12.5 \mu \mathrm{L}$ of the primer template described above. Add $1 \mu \mathrm{L}$ of undiluted PicoGreen to the mixture, allow to equilibrate for $5 \mathrm{~min}$ and then add pol III holoenzyme to initate the reaction.

Table 1 describes the simple and rapid protocol that has been established for performing large numbers of pol III holoenzyme assays. With appropriate changes in reaction conditions, this protocol should also be applicable to other replication systems.

\section{RESULTS AND DISCUSSION}

We explored the possibility of using PicoGreen to provide assays for nucleic acid replication. Since the dye does not fluoresce significantly in the presence of ssDNA, we reasoned that using templates with a low primer density should provide a low background and be adaptable to a fluorometric assay. The DNA polymerase III holoenzyme assay that uses elongation of a short primer generated at a unique site by $d n a \mathrm{G}$ primase on a long single-stranded template (5) provided an excellent candidate. Initial experiments indicated a large increase in fluorescence when PicoGreen was added after replication had occurred. Control experiments in which either enzyme or nucleic acid substrate were omitted from the reactions resulted in no observable fluorescence change.

To determine the correlation between the traditional isotopic assay and the fluorometric assay, aliquots from a series of polymerization reactions (containing $\left[{ }^{3} \mathrm{H}\right] \mathrm{TTP}$ ) were divided into 2 portions. One portion was subjected to the traditional filtration assay, and the other was assayed using PicoGreen (Figure 1). There was excellent agreement between the 2 data sets, indicating that the fluorometric assay accurately reflects the extent of polynucleotide synthesis.

We were able to extend the technique to measure RT activity by altering the primer-template ratio from equimolar with respect to nucleotides (8) to equimolar with respect to molecules. This provided a low initial fluorescence signal and a large fluorescence increase upon addition of RT (Figure 2).

The ability of the fluorometric assay to measure both complementary DNA strand synthesis on a synthetic RNA template and also the production of dsDNA from the single-stranded molecule, suggests this assay will be suitable for a wide range of applications in replication studies.

We are currently in the process of developing the assay to measure the activity of other enzymes that use nucleic acid substrates including DNA polymerase I. The most important considera-

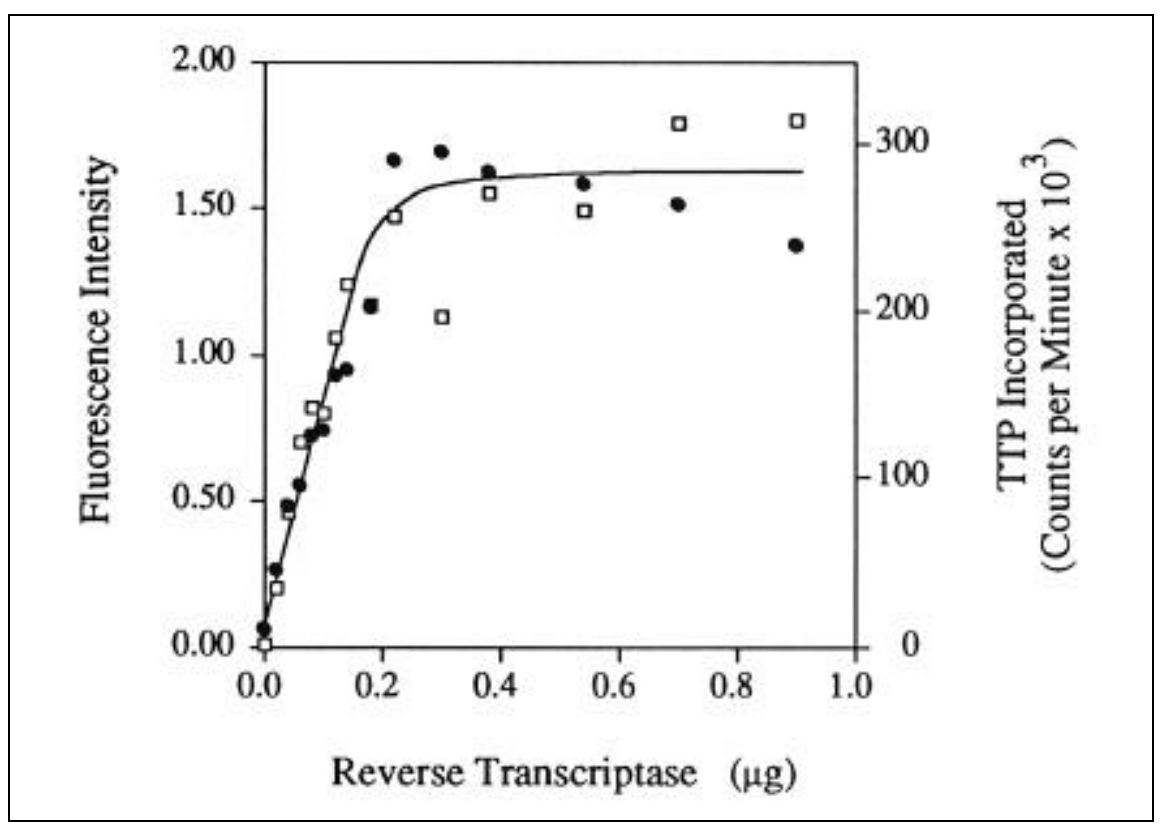

Figure 2. Comparison of fluorometric and isotopic assays for RT. Various amounts of RT were added to poly(rA) $)_{350}$ primed with oligo(dT) ${ }_{16}$ (see Materials and Methods). After a 10-min incubation, aliquots from the reactions were subject to either the PicoGreen fluorometric assay ( $)$ or the conventional isotopic assay $(\square)$. 
tion in the development of a PicoGreen assay is maximization of the fluorescence signal change. Conventional assays for DNA polymerase I measure either the nick-translation or gap-filling activities on activated DNA (7). The net change in the ratio of ss to dsDNA during DNA pol I-catalyzed reactions on this substrate is undetectable by PicoGreen. Consequently, we are developing nucleic acid substrates analogous to those used in this study for the RT assays. These involve synthetic DNA homopolymer templates to which are annealed relatively small amounts of oligomeric DNA primer.

The fluorometric assay was also performed using a plate reader. The results were essentially the same as those obtained on the SLM fluorometer (data not shown). It is clear that the fluorometric assays can be automated. We estimate that in the time it takes to do 100 isotopic assays (about $8 \mathrm{~h}$ ), it should be possible to do in excess of 700 fluorometric assays. Furthermore, using a plate reader, the cost of the fluorometric assay is less than half that of the isotopic assay.

By adding PicoGreen directly to the pol III holoenzyme-catalyzed reaction mixture, it was possible to directly and continuously monitor the extent of the polymerization in the SLM fluorometer (Figure 3). The presence of PicoGreen in the reaction mixture had no measur- able effect on the catalytic rate.

There is no apparent reason why multiple real-time reactions could not also be performed in a plate reader, given adequate temperature control of the plate. It is anticipated that this feature of the fluorometric assay will make it much simpler to characterize the kinetic properties of replication systems.

Unfortunately, attempts to monitor RT-catalyzed polymerization in realtime were frustrated by a significant inhibition (ca. 80\%) of the reaction in the presence of PicoGreen. This effect would appear to preclude quantitative real-time assays of RT systems.

The sensitivity of the fluorometric assay to contaminants was tested by assaying early fractions from a DNA polymerase III holoenzyme purification (data not shown). It was found that the material obtained after the initial ammonium sulfate fractionation (2) contained a contaminant (presumably DNA) that interfered with the assay. It is apparent that the assay is most useful with enzymes that have been purified to some extent.

In summary, we describe a simple, fast, economical and quantitative fluorometric assay for DNA polymerases and reverse transcriptases that is amenable to automation and should be of great value in the routine assay of these enzymes. The assay should be applicable to a wide range of replication enzymes and should provide a rapid and convenient method of screening for inhibitors that are effective against replication systems.

\section{REFERENCES}

1.Chavan, S.J. and H.J. Prochaska. 1995. Fluorometric measurement of reverse transcriptase activity with 4',6-diamidino-2-phenylindole. Anal. Biochem. 225:54-59.

2.Cull, M.G. and C.S. McHenry. 1995. Purification of Escherichia coli DNA polymerase III holoenzyme. Methods Enzymol. 262:2235 .

3.Frey, M.W., L.C. Sowers, D.P. Millar and S.J. Benkovic. 1995. The nucleotide analog 2-aminopurine as a spectroscopic probe of nucleotide incorporation by the Klenow fragment of Escherichia coli polymerase I and bacteriophage T4 DNA polymerase. Biochemistry 34:9185-9192.

4.Griep, M.A. 1995. Fluorescence recovery assay: a continuous assay for processive DNA polymerases applied specifically to DNA polymerase III holoenzyme. Anal. Biochem. 232:180-189.

5.Johanson, K.O. and C.S. McHenry. 1980. Purification and characterization of the $\beta$ subunit of the DNA polymerase III holoenzyme of Escherichia coli. J. Biol. Chem. 255:10984-10990.

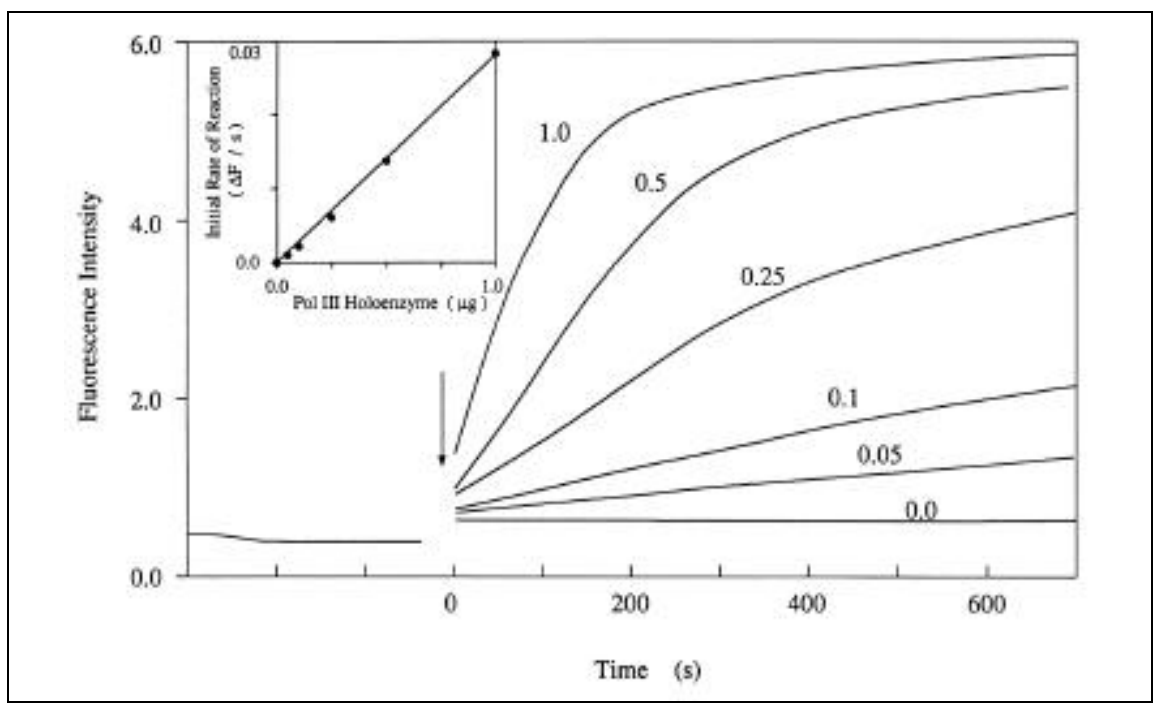

Figure 3. Continuous monitoring of the pol III holoenzyme-catalyzed replication of M13 Gori. Various amounts of pol III holoenzyme were added to cuvettes containing $100 \mu \mathrm{L}$ of polymerization reaction mixture and $1 \mu \mathrm{L}$ of PicoGreen. The time of addition is indicated by the arrow. The inset shows the initial reaction velocity as a function of the amount of enzyme added. 


\section{Short Technical Reports}

6.Okazaki, T. and A. Kornberg. 1964. Enzymatic synthesis of deoxyribonucleic acid. J. Biol. Chem. 239:259-268.

7.Setlow, P. 1974. DNA polymerase I from Escherichia coli. Methods Enzymol. 29:3-12.

8.Thimmig, R.L. and C.S. McHenry. 1993. Human immunodeficiency virus reverse transcriptase expression in Escherichia coli, purification, and characterization of a functionally and structurally asymmetric dimeric polymerase. J. Biol. Chem. 268:16528-16536.

Address correspondence to Mark Seville, Enzyco Inc., 191 University Blvd., Suite 305, Denver, CO 80206, USA.

Received 13 November 1995; accepted 10 April 1996.

Mark Seville, Anthony B. West $^{1}$, Millard G. Cull and Charles S. McHenry ${ }^{1}$

Enzyco Inc.

${ }^{1}$ University of Colorado Health

Sciences Center

Denver, CO, USA

\section{Novel Oxygenation System Supports Multilayer Growth of HeLa Cells}

BioTechniques 21:672-677 (October 1996)

\begin{abstract}
We have developed a novel substratum in which gelatin is bonded to a reservoir of perfluorodecalin using a perfluoroalkylating technique. This forms a stable substratum supporting good adhesion for cells. HeLa cells cultured on this substratum continued to grow exponentially after the surface was covered with a monolayer forming a tissue-like structure of more than 19 layers of cells. Histological sectioning and staining of the block of tissue formed revealed the presence of mitotic figures deep within the structure. Every cell was surrounded by other cells, similar to growth of cells in vivo. This technique opens up a new
\end{abstract}

approach to studying problems involved in cell-cell interaction and development of histotypic structures in vitro.

\section{INTRODUCTION}

Growth of anchorage-dependent cells in culture has usually been restricted to a monolayer with relatively low cell densities per square centimeter. This limitation is thought to be due to the low solubility of oxygen and slow rate of diffusion in growth medium. The use of gas permeable membranes and hollow fibers perfused with oxygenated medium have been used in an effort to improve oxygenation at the substratum. These methods have resulted in significant improvements in function and morphology of the cells, and under certain conditions, cells can be grown two or three layers deep (5-8, 10). However, the amount of oxygen available to the cells in these systems 